\title{
Noradrenergic Response to Intravenous Yohimbine in Patients with Depression and Comorbidity of Depression and Panic
}

\author{
Sally K. Guthrie, Leon Grunhaus, Atul C. Pande, and M. Hariharan
}

\begin{abstract}
Adrenergic resporise following infusions of yohimbine or normal saline was evaluated in 9 control subjects, 8 patients suffering from a major depressive episode (MDE), and 12 patients suffering from concurrent $M D E$ and panic disorder $(M D E+P)$. Blood was drawn at -20 . $0,5,10,20,45$, and 90 min following the infusions, and assayed for norepinephrine (NE) and 3-methoxy-4-hydroxy-phenyl glycol (MHPG). Although the patient groups exhibited higher baseline NF concentrations, and a greater NE area under the plasma concentration versus time curve $\left(A \cup C_{0-90}\right)$ during the yohimbine infusion, the differences were not statistically significant. Baseline $N E$ was significantly correlated with the $N E A U C_{0-90}$ in all three groups. suggesting that, although the NE system may be dysregulated in the MDE and MDE +P patients, the $N E$ system still appears to respond somewhat predictably following a challenge, even though the actual magnitude of response may vary.
\end{abstract}

Key Words: Comorbidity, depression, panic, norepinephrine, MHPG, yohimbine

\section{Introduction}

Dysfunction of $\alpha_{2}$-adrenergic receptors has been implicated in both melio à apressive illness and panic disorder (Price et al 1981; Charney and Heninger 1985). Yohimbine, an $\alpha_{2}$ receptor antagonist, has been used as a probe to investigate the functioning of the norepinephrine (NE) system. When administered to individuals suffering from panic disorder, yohimbine precipitates a panic attack in the majority of these individuals (Charney et al 1992), and causes significant increases in 3-methoxy-4-hydroxyphenylglycol (MHPG). However, when yohimbine is administered to depressed persons it does not cause a sig-

\footnotetext{
From the College of Pharmacy and Depurtinent of Psychiatry (SKG) The University of Michigan, and the Department of Psychiatry. The University of Michigan Medical School The University of Michigan. Ann Arbor, MI (LG, MH); and the Lilly Research Laboratories, Lilly Copporate Center, Indianapolis, IN (ACP). Address reprint requests to Sally K. Guthrie. Pharm D. College of Pharmacy. The University of Michigan. Ann Arbor, Ml 48109-1065.

Received October 3, 1992; revised July 15, 1993

(C) 1993 Society of Biological Psychiatry
}

nificantly greater MHPG response when compared with controls (Price et al 1986).

Comorbidity of depression and panic is found in a proportion of patients with either disorder but studies exploring $\alpha_{2}$-adrenergic function in patisnts with comorbidity have not been published. We have used à yuinimbine challenge paradigm to compare NE system functioning among individuals suffering from major depressive illness with $(\mathrm{MDE}+\mathrm{P})$ or without (MDE) panic disorder and healthy control subjects, to test the hypothesis that NE response to yohimbine is more prominent in the comorbid (MDE + P) patients.

\section{Methods}

Twenty-nine individuals received a yohimbine challenge, including: Nine control subjects, eight depressed subjects (MDE), and 12 persons suffering from concurrent depression and panic disorder (MDE $+\mathrm{P}$ ). All subjects received 
sion and panic disorder (MDE + P). All subjects received a physical examination, blood chemistry, complete blood count, and electrocardiogram, as well as a low monoamine diet beginning $72 \mathrm{hr}$ prior to, and lasting throughout, the study period.

The nine, medication-free control subjects ( 7 women, 2 men, 26 to 56 years old) were found to be free of psychiatric illness. Eight inpatients (6 women, 2 men, 18 to 48 years old) who met DSM-Ill diagnostic criteria for major depressive episode were included. Twelve additional inpatients (9 women, 3 men, 25 to 52 years old) met the DSM-III diagnostic criteria for panic disorder as well as for major depressive episode. All subjects were drug-free for 14 days prior to the study and all women were studied during the first 10 days of their menstrual cycle.

Subjects participated in two study sessions; at 7 AM all subjects were placed at bed rest while an intravenous catheter was placed in the arm and bed rest was maintained throughout the procedure. At approximately 8:30 AM on the first day all subjects received a double-blind, bolus intravenous injection of either normal saline $(20 \mathrm{ml})$ or $0.15 \mathrm{mg} / \mathrm{kg}$ (maximum $10 \mathrm{mg}$ ) of yohimbine $\mathrm{HCl}$ $(0.45 \mathrm{mg} / \mathrm{ml}$ solution). We concluded that this dose was likely to induce an increase in sympathetic outflow (Grossman et al 1991; Goldstein et al 1991), while maintaining specificity for $\alpha_{2}$ receptors (Johnston and File 1989, Ramage and Tomlinson 1985). Blood samples were drawn at $-20,0,5,10,20,45$, and 90 min following yohimbine administration. Plasma NE was determined using a modification of a previously published method (Eisenhofer et al 1986) and MHPG was determined by the method developed in our laboratory (Hariharan et al 1989).

The baseline values for NE and MHPG on the placebo day and on the yohimbine day were compared using an unpaired $t$-test, and comparisons among the three groups of subjects (control, MDE, MDE + P) were accomplished using an analysis of variance (ANOVA) for repeated measures. The areas under the concentration versus time curves for both NE (NE AUC $0-90$ ) and MHPG (MHPG AUC ${ }_{0-90}$ ) were calculated using the trapezoidal method, adjusting for the baseline value. On the yohimbine day the NE and MHPG baseline values were correlated with NE $A U_{0-90}$ and MHPG $A U_{0-90}$, respectively. Natural $\log$ transformation of all NE and MHPG values was performed prior to statistical comparisons.

\section{Results}

Baseline NE and MHPG values were not significantly different between the yohimbine and placebo study days (Table 1). Neither of these baseline values differ among the three groups on either the placebo or yohimbine days.

All three groups showed significantly $(p<0.01$, for each) higher $\mathrm{NE} \mathrm{AUC}_{0-90}$ following yohimbine, when compared with the placebo day (Figure 1). The mean NE AUC $_{0-90}$ following yohimbine in the MDE $+\mathrm{P}$ and the MDE groups did not differ significantly from the control group. Nor did the group differences in MHPG $\mathrm{AUC}_{0-90}$ achieve statistical significance. The interindividual variability in all groups was very large, and probably contributed to the lack of statistically significant differences.

On the yohimbine day correlations between baseline $\mathrm{NE}$ and $\mathrm{NE} \mathrm{AUC}_{0-90}$, were significant in the control $(r=0.77, p=0.014)$, the $\operatorname{MDE}(r=0.79, p=0.021)$, and the MDE $+\mathrm{P}(r=0.75, p=0.005)$ groups. The correlation between baseline MHPG and MHPG AUC $\mathrm{C}_{0-90}$ following yohimbine was not significant in any of the groups.

Table 1. Norepinephrine and MHPG Baseline and $\mathrm{AUC}_{0-90}$ Values $(X \pm S D)$

\begin{tabular}{|c|c|c|c|c|c|c|c|c|}
\hline \multirow[b]{3}{*}{ Controls } & \multicolumn{4}{|c|}{ Normal saline day } & \multicolumn{4}{|c|}{ Yohimbine day } \\
\hline & \multirow{2}{*}{$\begin{array}{c}\begin{array}{c}\text { baseline } \\
\text { NE } \\
(\mathrm{pg} / \mathrm{ml})\end{array} \\
247.4\end{array}$} & \multirow{2}{*}{$\begin{array}{c}\begin{array}{c}\text { baseline } \\
\text { MHPG } \\
(p g / m /)\end{array} \\
3.23\end{array}$} & \multirow{2}{*}{$\begin{array}{c}\begin{array}{c}\mathrm{NE} \\
\mathrm{AU} \mathrm{C}_{0-40} \\
(p \mathrm{~g} / \mathrm{m}\end{array} \\
1857\end{array}$} & \multirow{2}{*}{$\begin{array}{l}\begin{array}{c}\text { MHPG } \\
\text { AUC } \\
\text { min) }\end{array} \\
6.4\end{array}$} & \multirow{2}{*}{$\begin{array}{c}\begin{array}{c}\text { baseline } \\
\mathrm{NE}\end{array} \\
(\mathrm{pg} / \mathrm{ml})\end{array}$} & \multirow{2}{*}{$\begin{array}{c}\begin{array}{c}\text { baseline } \\
\text { MHPC } \\
(p g / m l)\end{array} \\
3.17\end{array}$} & \multirow{2}{*}{$\begin{array}{c}\text { NE } \\
\begin{array}{c}\text { AUC }^{2-90} \\
(p g / m)\end{array} \\
41077^{\circ}\end{array}$} & \multirow{2}{*}{ 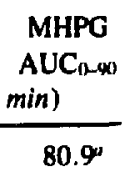 } \\
\hline & & & & & & & & \\
\hline$\pm \mathrm{SD}$ & 132.5 & 0.69 & 3638 & 27.2 & 83.9 & 0.69 & 28122 & 53.5 \\
\hline$(n)$ & 9 & 9 & 8 & 9 & 9 & 9 & 9 & 9 \\
\hline MDE & 295.5 & 2.68 & 3782 & 45.0 & 299.6 & 2.66 & $40773^{\circ}$ & 61.3 \\
\hline $\pm S D$ & 93.1 & 1.11 & 11297 & 78.1 & 122.2 & 1.08 & 28763 & 36.6 \\
\hline$(n)$ & 8 & 8 & 8 & 6 & 8 & 8 & 8 & 8 \\
\hline $\mathrm{MDE}+\mathrm{P}$ & 295.0 & 3.11 & 3031 & -12.9 & 305.8 & 3.03 & $61099^{\prime \prime}$ & $78.5^{\circ}$ \\
\hline$\pm \mathrm{SD}$ & 151.7 & 0.87 & 6252 & 19.6 & 158.4 & 0.81 & 40727 & 38.3 \\
\hline$(n)$ & 12 & 12 & 12 & 12 & 12 & 12 & 12 & 12 \\
\hline
\end{tabular}

$a_{p}<0.05$. using paired t-test5, Normal saline day compared with Yohimbine day. 


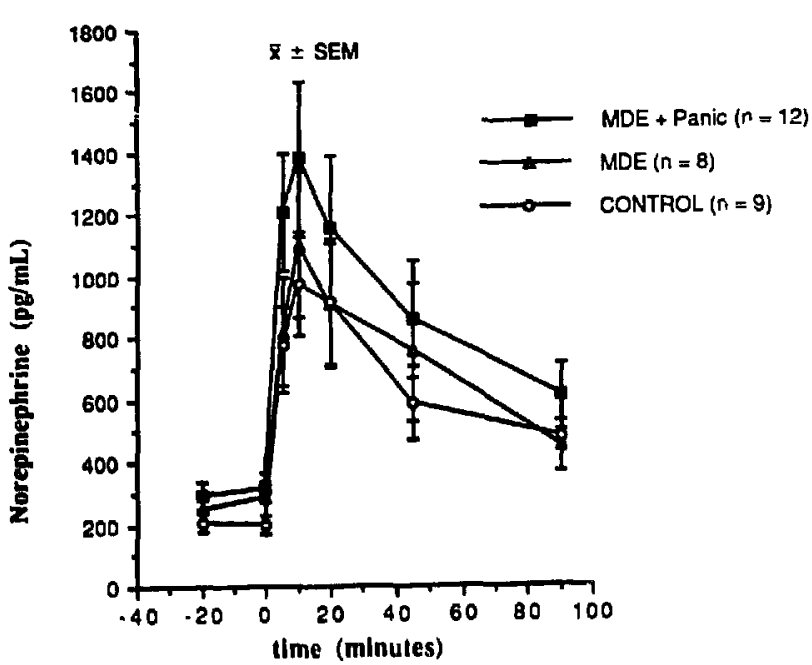

Figure 1. Norepinephrine response following yohimbine administration in MDE + $P, M D E$, and control groups. There were no statistically significant intergroup differences among the groups.

\section{Discussion}

Panic disorder may be concurrently present in approximately $30 \%$ of patients suffering from MDE (Leckman et al 1983; Fawcett and Kravitz 1983). This subgroup of depressed patients may exhibit a more severe disease course and respond less well to treatment (Leckman et al 1983; Grunhaus et al 1986), so there is reason to suspect that this subgroup may exhibit a unique response to a norad$r$ ergic challenge. Although response of $\mathrm{MDE}+\mathrm{P}$ to a y-uimbine challenge has not previously been reported, Price et al (1986) reported that the MHPG response following yohimbine did not differ when patients suffering

\section{References}

Charney DS, Heninger GR (1985): Noradrenergic function and the mechanism of action of antianxiety treatment II. The effect of long-term imipramine treatment. Arch Gen Psychiatry 42:473-481.

Charney DS, Woods SW, Goodman WK, Heninger GR (1987) Neurobiological mechanisms of panic anxiety: biochemical and behavioral correlates of yohimbine-induced panic attacks. Am J Psychiatry 144:1030-1036.

Charney DS, Woods SW, Kyrstal JH, Nagy LM, Heninger GR (1992) Noradrenergic neuronal dysregulation in panic disorder: the effects of intravenous yohimbine and clonidine in panic disorder patients. Acta Psychiatr Scand 36:273-282.

Eisenhofer G, Golóstein DS, Stull R, et al (1986) Simultaneous liquid chromatographic determination of 3,4-dihydroxyphenylglycol, catecholamines and 3,4-dihydroxyphenylalanine in plasma and their responses to inhibition of monoamine oxidase. Clin Chem 32:2030-2033.

Fawcett J, Kravitz HM (1983) Anxiety syndromes and their from depression were compared with controls. Similarly, we found no significant difference in MHPG $A U C_{0-90}$ between the control and MDE groups. We also found no significant difference in MHPG AUC $_{0-90}$ between the $\mathrm{MDE}+\mathrm{P}$ and the control (or MDE alone) groups. This was unexpected because Charney et al $(1992,1987)$ has documented significantly greater MHPG concentrations at 2,3 , and $4 \mathrm{hr}$ following yohimbine in patients suffering from panic disorder. In our patients the comorbidity of depression and panic may have attenuated the response that would have been seen if patients were suffering from panic alone.

The relationship of baseline $\mathrm{NE}$ to $\mathrm{NE} \mathrm{AUC}_{0-90}$ following the yohimbine challenge was determined by correlating baseline $\mathrm{NE}$ with $\mathrm{NE} \mathrm{AUC}_{0-90}$. In all groups a significant correlation was found between the baseline $\mathrm{NE}$ and the $\mathrm{NE}^{\mathrm{AUC}} \mathrm{C}_{0-90}$ following yohimbine, suggesting that, although the relationship may differ among the different groups, the NE output following $\alpha_{2}$ blockade is directly related to the baseline NE tone. This implies that, although the NE system may be dysregulated in MDE and MDE + $\mathbf{P}$ patients, the system is still working in synchrony, such that it can respond somewhat predictably following a challenge, even though the actual magnitude of the response may vary depending on the patient population.

Overall, we found that all groups exhibited increases in NE and MHPG following yohimbine, but the large interindividual variability precludes any firm conclusions regarding a differential response among our groups. Although a slightly higher mean NE response to yohimbine in our patient groups, compared with controls, suggests that, while significant differences may exist, a larger sample size would be necessaiy to exhibit such a difference.

relationship to depressive illness. $J$ Clin Psychiatry 44 (8, Sec 2):8-11.

Goldstein DS, Grossman E, Listwai S, Folio CJ (1991) Sympathetic reactivity during a yohimbine challenge test in essential hypertension. Hypertension 18[suppl III]:III-40-III48.

Grossman E, Rea RF, Hoffman A, Goldstein DS (1991) Yohimbine increases sympathetic nerve activity and norepinephrine spillover in normal volunteers. Am J Physiol 260:RI42R147.

Grunhaus L, Rabin D, Greden JF (1986) Simultaneous panic and depressive disorders: Response to antidepressant treatments. $J$ Clin Psychiatry 47:4-7.

Hariharan M, Van Noord T, Cameron OG, Curtis GC, Ostrow DG (1989) Free 3methoxy-4-hydroxyphenylglycol determined in plasma by liquid chromatographly with coulometric detection. Clin Chem 35:202-205.

Johnston AA, File SE (1989) Yohimbine's anxiogenic action: 
evidence for noradrenergic and dopaminergic sites. Pharmacol Biochem Behav 32:151-156.

Leckman JF, Weissman MM, Merikangas KR, Pauls DS, Prusoff BA (1983) Panic disorder and major depression. increased risk of depression, alcoholism, panic, and phobic disorders in families of depressed probands with panic disorder. Arch Gen Psychiatry 40:1055-1060.
Price LH, Chamey DS, Rubin AL, Heninger GR (1986) $\alpha_{2}$ Adrenergic receptor function in depression. The cortisol response to yohimbine. Arch Gen Psychiatry 43:849-858.

Ramage AG, Tomlinson A (1985) The effect of yohimbine, WY 26392 and idazoxan on sympathetic nerve activity. Eur $J$ Pharmacol 109:153-160. 